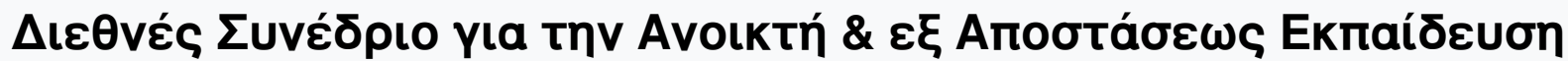

Tón. 8, Ap. 4B (2015)

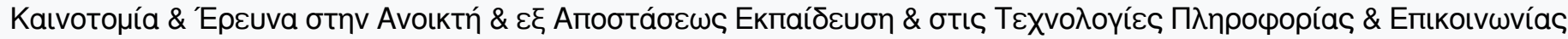

| ПраKüiká

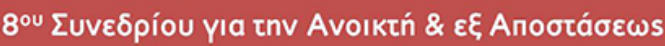

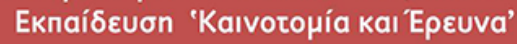

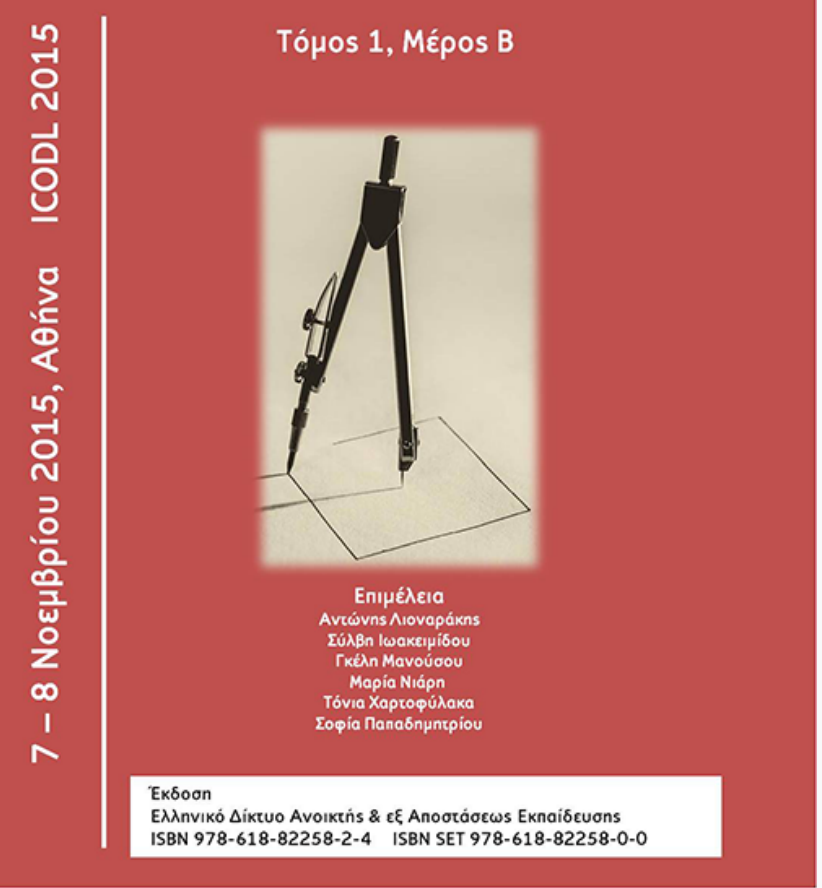

The implementation of Flex methodology in a language class and the use of the Community of inquiry (Col) framework

Antonia Fyrigou

doi: $10.12681 /$ icodl. 55 


\title{
The implementation of $i^{2}$ Flex methodology in a language class and the use of the Community of inquiry (CoI) framework
}

\author{
Antonia Fyrigou, Ph.D. \\ American Community Schools (ACS) of Athens, Greece \\ Language Teacher \\ Coordinator of Languages Department \\ firigout@acs.gr
}

\begin{abstract}
In this paper, I will share and discuss my involvement with the $i^{2}$ Flex in the two past academic years following the educational needs of the new generation students. First, I will describe how I went about my first encounter with $i^{2}$ Flex in the IB French class as a member of the pilot $i^{2}$ Flex faculty at ACS Athens, namely: a) I will present the instructional (re-) design of my Moodle class to reflect the new teaching methodology, and b) I will explain the need to evaluate this pilot year via an appropriate framework. Then, I will move on, describing my class in the second year, from how $i^{2}$ Flex was at this point implemented to how it was evaluated and what data was collected from the students. Finally, my goal is to share under the umbrella of best practices how meaningful and efficient the $\mathrm{i}^{2}$ Flex is, taking in consideration the new role of the teacher in and out of class and the student's unique potential. This experience is a new powerful learning process for both sides, since teacher and students are on the same boat with a unique goal to achieve the best quality of learning.
\end{abstract}

Key-words: $i^{2}$ Flex, Community of Inquiry, Blended Learning, International Baccalaureate, Second Language Teaching, Instructional Design

\section{Пєрі́ $\eta \psi \eta$}

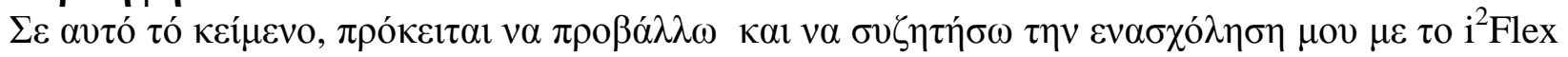

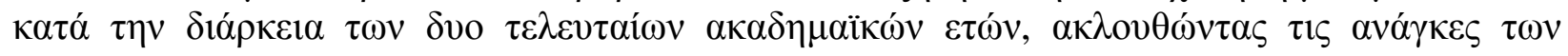

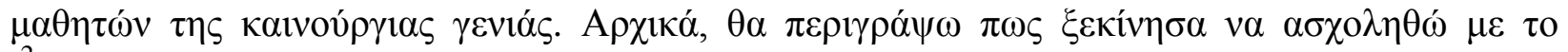

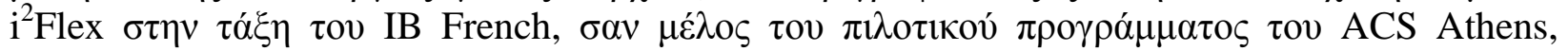

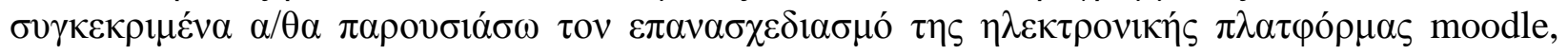

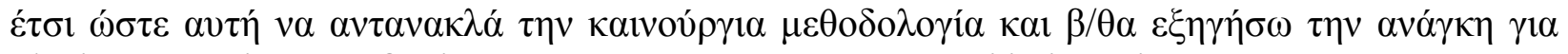

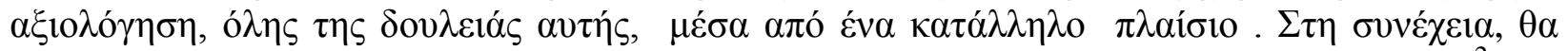

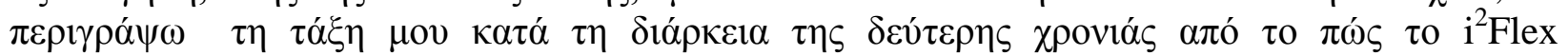

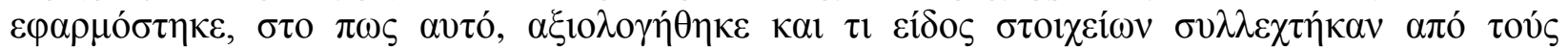

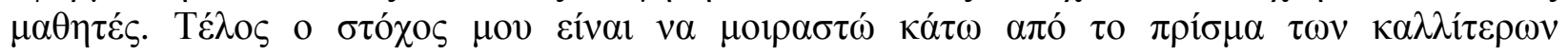

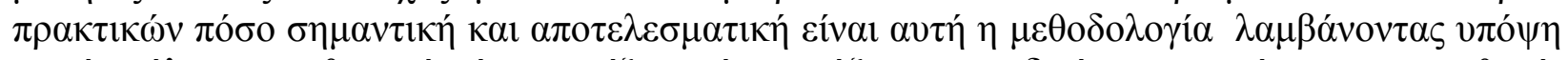

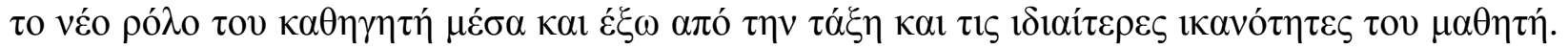

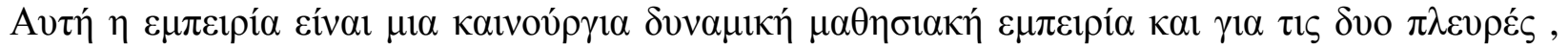

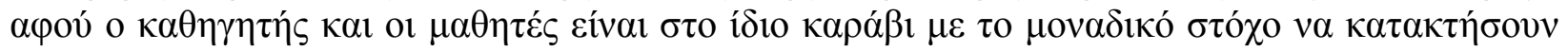

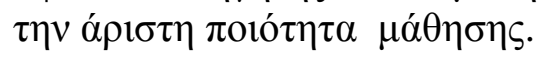




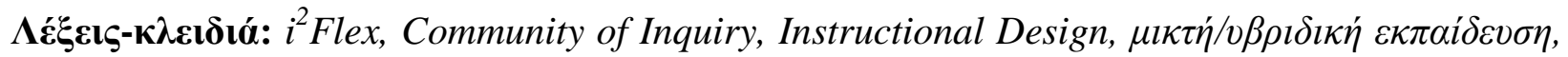

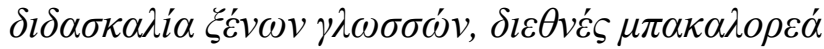

\section{Introduction and Overview}

\subsection{ACS Athens and $21^{\text {st }}$ Century Education}

When Albert Einstein said: "The true sign of intelligence is not knowledge but imagination" he could probably not predict that the $21^{\text {st }}$ century's learning would be so much related with imagination and creativity, where, creativity would be the center of the world. At ACS Athens, according to our philosophy, we challenge our students to use their unique potential and create their own learning. Having that in mind and at the same time, realizing that in our days we have a new model of learners who prefer hyperlinked information, and enjoy working in teams collaborating, sharing and exchanging ideas, we understand that the teacher gets a more demanding role, as she needs to prepare students not only for their university studies but also for the future as global citizen. Therefore, a lifelong learner teacher, who wants to have a proactive role, needs to take the risk and try innovative methods of teaching and learning. When last year, we had been exposed to the $\mathrm{i}^{2}$ Flex methodology, I could not imagine that this methodology would change so drastically the entire learning concept and my teaching philosophy. For someone who didn't have the chance to get exposed to this fruitful methodology, the definition of $i^{2}$ Flex is clear if we have in mind that the first $i$ stands for independent student learning, the second I stands for inquiry based student learning and by Flex we mean a face-to-face, flexible, guided student learning supported by technology

My own $\mathrm{i}^{2}$ Flex experience is based on my French IB class during the last 2 years that I implement this innovative methodology. Even though I teach French IB 16 consecutive years this new approach of teaching and learning, inspired me to move further and investigate in depth students' satisfaction via the CoI (2000) Community of Inquiry framework. In particular, in the $2^{\text {nd }}$ year, this investigation became the focus of my own Action Research project in order to explore the effects of the $\mathrm{i}^{2}$ Flex in my French IB class.

Essentially, the CoI (2000), assisted me to look at the $\mathrm{i}^{2}$ Flex elements which improve learning in a multi level language class and to see how students perceive the implementation of this innovative methodology. The CoI (2000) helped me to research in depth the advantages and the shift in teaching and learning by recording results from the CoI (2000) survey, teacher's journal, and students' work. My own observations in class and reflections also were taken in consideration.

Students already knew from the previous year, about the $\mathrm{i}^{2}$ Flex and since it's an IB class, I was lucky to work with them for a second year using the CoI (2000) to make the connection with the

$\mathrm{i}^{2}$ Flex methodology and get a clearer picture of the educational experience. My action research focus and inquiry was to explore if students get more engaged, become independent and active learners, and perhaps achieve an overall higher academic performance.

\section{Literature review}

Talking about blended learning, we have in our mind a "formal education program" where the learner is doing a part of his work online and another part face to face (www.teachthought.com). This kind of teaching and learning is a new experience for those who have been educated a long time ago, this new approach is creating a new experience and gives a different direction (www.teachthought.com). A thoughtful educator could always doubt on which is the best 
percentage of digital and online learning, or which is the best place to meet for the face to face time, or how much online instructional time should we use. Nonstop questions about blended learning and a long path to follow, but the most important is not the theoretical framework but the fact that blended learning is the answer to today's requirements for global citizen.

\section{1. $i^{2}$ Flex and blended learning}

Connected with blended learning, the $\mathrm{i}^{2}$ Flex methodology incorporates an integrated use of technology that enhances content, and it is a carefully selected and interesting application to a specific unit of study. From the very first moment that a teacher gets to know the $i^{2}$ Flex, she understands that this innovative methodology has the following characteristics: $i^{2}=i x i$, where the first $\mathrm{i}$ stands for independent student learning, utilizing different online reading books and other reliable sources, the second one for inquiry-based student learning, where the faculty checks the student's findings and sends back guidance which allows the student to improve the quality of the assignment and continue in the right direction and the final step, the face-to-face, flexible part, where students and faculty meet face to face (e.g. in the classroom, in a museum, during a fieldtrip or anywhere else) and the assignment is completed. This is the moment that the following are taking place: The teacher knows in advance whether the student understood the topic in depth, and the quality of the work done.

\subsection{CoI and $i^{2}$ Flex}

After the first year of the $\mathrm{i}^{2}$ Flex implementation, where everything was new for both sides, and feeling excited about this refreshing methodology, I decided to move on to the next step and evaluate the experience via an appropriate framework. It was then that I was introduced to the Community of Inquiry (CoI, 2000) framework. The evaluation of the implementation of the $\mathrm{i}^{2}$ Flex could not take place if we didn't have the possibility to use the Community of Inquiry framework which is coming as a gift to let us evaluate the educational experience with the use of this innovative methodology. For all intents and purposes, this educational tool assists all of us who have already experienced the $\mathrm{i}^{2}$ Flex approach, to better understand how the students perceive the educational experience and of course gives answers and solutions to different areas. It was necessary to modify the original CoI (2000) framework in order this, to meet the real conditions of the $i^{2}$ Flex implementation. The initiation of the CoI (2000) framework is significant not only because we can get important info about the cognitive presence and see exactly how topics and material increase students interest, but also because we can collect data on how course activities pick students' curiosity. At the same time it's easy to estimate students' feel motivation, utilizing a variety of material to explore problems posed in the relevant course.

\section{3. $i^{2}$ Flex in the IB French class}

\subsection{Introduction}

In this section, I will present my involvement with $i^{2}$ Flex in the past two school years. But before that, it is important to describe my class which included, for both years, two different levels of French IB students, 11 and 12 graders. First, I will describe how I went about my first encounter with $i^{2}$ Flex in the IB French class as a member of the pilot $i^{2}$ Flex faculty at ACS Athens, namely: a) the instructional (re-) design of my Moodle shell to reflect the new teaching methodology, and b) the need to evaluate this pilot year via an appropriate framework. Then, I will move on to describing my class in the second year, from how $i^{2}$ Flex was now implemented 
to how it was evaluated and what data was collected from the students. Essentially, I wanted to see how my students perceive their learning putting on the spot the three presences; the cognitive, the social and the teaching presence.

\subsection{Experimentation: Pilot i $i^{2}$ Flex year (2013-2014)}

In this pilot year my purpose was to come to terms with available technology and develop my technology skills further. I felt that both of these skills were prerequisite to redesigning my course in the $i^{2}$ Flex way. As a result I totally reconsidered my moodle shell online and fully adopted the $i^{2}$ Flex moodle template that ACS had developed

The design of the $i^{2}$ Flex French course shell in Moodle reflects precisely to the concept of the course, the Morfosis educational paradigm and to what is practically needed to teach that successfully.

The idea of the design and the organization of the French course shell were based in teaching experience and the aim was to be meaningful and clear for the student. This new avenue for high quality learning offers a holistic and innovative approach which ensures an harmonious teaching process. In particular, when a student faces his $\mathrm{i}^{2}$ Flex moodle shell page, the first to see is the Home page where he will find a welcome greeting, all the different tabs with the diverse areas of the syllabus and a News Forum, with all the important announcements and deadlines for assignments or other significant issues.

There is also a Virtual Coffee Shop, which is a wonderful environment for students and faculty to post questions, concerns, topics for discussion or any other ideas; this gives the possibility to students to interact and exchange among them. The Home page also includes Virtual Office hours arranged by appointment which offer synchronous communication via chat or asynchronous and of course a calendar which facilitates students to schedule and organize effectively their work.

Furthermore, the Welcome! Start Here tab includes info about the instructor, a short bionote clip, through voice thread and a bio which allows students to know better their instructor. Last but not least, the shell provides all the necessary info about how to navigate the course

Additionally, it is available, data about technical student support and of course the course rules which define the relation between the teacher with the students as well with the online learning environment. The Home page includes as well a tab within the course syllabus in detail and all the guidance the student needs to have such as learning goals, standards, benchmarks and performance indicators, textbooks information, related links and everything about the course description as the basis of the course material and concept.

There is always, in all different areas of the French Moodle shell, a clear picture and info about grading and a detailed description of homework, assignments, exams, projects and of course additional resources as maps, visual material, interviews, films and other helpful material. The assignments posted by the faculty and the students' submissions are categorized according to the different areas of the syllabus and there are also audio samples and a gallery of students' exceptional work which serve students to improve their own work.

The use of VoiceThread ${ }^{\circledR}$ (Figure 4) is an innovative and attractive tool for a language class, including visual and written material, where students can make their submissions from home and feel proud and confident -especially those who do not feel very positive with their oral in front of the class. Principally, we name VoiceThread ${ }^{\circledR}$ any recording using or not a camera which 
sends voice, or voice and picture, or video and instructional material. It can be used from teacher's side for online instruction but also from student's side as an assignment submission.

\subsection{Transformation: $i^{2}$ Flex Full Integration (2014-2015)}

In the beginning of the second year, I began to redesign my $i^{2}$ Flex class with a special goal to explore the element of the three presences. The transformation of my instructional design happened with the application of ASSURE model . The ASSURE model is an ISD (Instructional Systems Design) process that was modified to be used by teachers in the regular classroom. The ISD process is one in which teachers and trainers can use to design and develop the most appropriate learning environment (www.instructionaldesign.org).

As I was using the $\mathrm{i}^{2}$ Flex methodology for the second year and realizing my target audience and the characteristics of my students' learning, I analyzed the data and stated my objectives. What my students needed to learn was all the different parts of the French IB; essentially, they had to be able to understand different kind of texts and be able to answer comprehension questions, write essays and of course speak fluently the language and present different topics expressing their opinion..

\subsection{Illustrating the Implementation of $\mathrm{i}^{2}$ Flex via "Cultural Diversity"}

The teacher posts on moodle an assignment where the students need to go on VoiceThread $®$ and find:

a/ a short lecture from me about the topic and some instructions they need to follow

$\mathrm{b} / \mathrm{a}$ picture that I also posted on the same topic.

Their work consists:

$\mathrm{i}^{2}$ : i $\mathrm{x}$ i (include both $\mathrm{i}$ concepts)

A/ to research online (WEB) and find a related article about the cultural diversity and submit it on Moodle

B/record a VoiceThread ${ }^{\circledR}$ presentation based on the article they found, and the picture posted by me.

Face to Face flexible part

$\mathrm{C} /$ Students and teacher will get in the atrium to engage a discussion based on their research findings after getting feedback electronically from their teacher. Teacher will send back feedback and instructions via VT before the face to face step.

\section{Using the CoI to gauge student satisfaction}

In order to get accurate data from students I created two surveys (Figure 7) using the CoI (2000) modified where my students were asked to take a few minutes and complete a survey which covered the three different presences in order to provide me info about their learning experience via the $\mathrm{i}^{2}$ Flex methodology. I was at the same time assuring them that this would be anonymous in order for them to feel comfortable and write exactly how they felt without having any concern about their grade in class. This data was extremely helpful and precious for me as it was a way to understand the application of the methodology putting on the spot my presence as a teacher, the cognitive part and last but not least the social presence and how this helped them to become active and creative learners 


\section{Reflection on employing the CoI as a vehicle to evaluate the $i^{2}$ Flex experience of the learner}

When I started implementing the $\mathrm{i}^{2}$ Flex I could not imagine how this would change my teaching philosophy but mostly how this would be so valuable for students' learning! The $i^{2}$ Flex implementation came as a gift, to solve problems that often appear in multi level classes. First of all, multi-level students have become more engaged and the blended course provides innovative ways of learning at home by increasing new educational opportunities for students, especially those who do not feel comfortable with the language. It also gives the flexibility to students to work at different times and complete their work at any hour of the day seven days per week. Learning has become more complex and much more attractive since the learning environment is not any more only the classroom but the real world! The virtual office hours arranged by appointment through ACS gmail offers students more learning flexibility, an innovative way of communication and engages them to take responsibility. As educator, I strongly believe that $i^{2}$ Flex is an effective integration of technology which stimulates students to attempt more complex tasks and material. $\mathrm{i}^{2}$ Flex students are moving away from passive reception of information to build their own learning. Teaching has also moved from textbooks to multiple representations and expressions and learning has changed from reception of knowledge and interaction to active engagement in the process of learning.

Finally, the use of CoI (2000), helps students learn how to think independently, search, collect their thoughts, and get prepared how to communicate with the faculty. Therefore, critical thinking is developed as also, by following instructions from the faculty, students learn how to" listen" and they become able to identify their own needs. Furthermore, faculty understands weather the student enjoys the $i^{2}$ Flex methodology and learns better either he challenges in specific areas. Additionally, following all the steps above, the faculty can design, and distribute meaningful, appropriate and creative assessment materials to students. Collecting students' feedback helps faculty to make the shift in planning and delivering knowledge in a beneficial way for students!

As a conclusion, the introduction of the CoI (2000) gives faculty the opportunity to offer a more efficient, better organized and much more motivating teaching and provides students a high quality student-centered, individual approach of learning.

Personally, my own experience with $\mathrm{i}^{2}$ Flex and the Community of Inquiry framework makes me feel confident that this technological integration in my multi-level IB class has moved teaching and learning to a new, flexible conceptualization of creative learning. The introduction of $i^{2}$ Flex with the use of CoI (2000), is working smoothly and offers a more efficient, better organized teaching, providing a high quality student -centered, individual learning.

\section{Final thoughts and a few challenges}

The application of the CoI (2000) in class is meaningful and gives new perspectives to realize how the students perceive the learning process and the implementation of the $\mathrm{i}^{2}$ Flex methodology. Observing the online or web based communication, the cognitive presence and the teaching part, we can evaluate all the educational experience and we can make valuable recommendations for the future. Of course, as everything is still new and as a lifelong learner, I always challenge myself to do better and better; I believe that there is a lot of room for improvements and reconsiderations all over the use of $i^{2}$ Flex and the Community of Inquiry framework. At the same time we need to consider different challenges that always appear 
throughout the learning process, especially if the students were never exposed prior to blended learning. The technology part is easy and motivating for students, the frustration is mostly in the different delivery and assignment submission type. It's also the shift in students mind about their new responsibilities. The most important is to continuously try to be pro active in teaching and learning and identify the needs of our students for their future. As Einstein said: "Intellectual growth should commence at birth and cease only at death", we should never stop trying to get better and better, no matter from which capacity we serve the educational experience".

\section{References}

Advantages

$$
\&
$$

Limitations

of

Blended

Learning

http://www.researchgate.net/post/What are the advantages and limitations of Blended learning

ASSURE. (2015). Available at: http://www.instructionaldesign.org/models/assure.html

Avgerinou, M.D., \& Gialamas, S. (2014). i $^{2}$ Flex: Integrating a large-scale technology supported educational innovation in a K-12 international school setting. 2014 IEEE $14^{\text {th }}$ International Conference on Advanced Learning Technologies (pp. 742-743). DOI 10.1109/ICALT.2014.217

Blended Learning- Definition. (2013). http://www.teachthought.com/blended-learning-2/the-definition-of-blendedlearning/

Blended Learning. (2015). http://www.knewton.com/blog/ed-tech/blended-learning/

Blended Teaching \& Learning. (2015). http://www.teachthought.com/wp-content/uploads/2013/04/BlendedLearning-Teaching-Infographic.jpg

Center for Excellence in Learning and Teaching. (2015). Revised Bloom's Taxonomy. Available at: http://www.celt.iastate.edu/teaching-resources/effective-practice/revised-blooms-taxonomy/

Community of Inquiry. (2015). https://coi.athabascau.ca/

Community of Inquiry Framework. (2015). http://www.slideshare.net/josemota/community-of-inquiry-framework

Community of $\quad$ Inquiry Framework

(2015).

http://www.academia.edu/398997/A_Constructivist_Approach to_Online Learning The Community of Inquiry_Framework

Community of Inquiry Model. (2015). http://edutechwiki.unige.ch/en/Community_of_inquiry_model

Constructing effective Online Learning Environments via the Community of Inquiry (CoI)(n.d.). Retrieved October 10, 2015 from: http://www.iddblog.org/?p=841

Global Morfosis Paradigm. (2015). www.acs.gr

Reed, K. (2014, May 7). Student-centered learning: How to implement a blended learning program. Ed Tech.

Student View of Blended Learning. http://www.ecsu.edu/academics/offices/distanceeducation/docs/studentViewBlendedLearning.pdf (2015). VoiceThread. (2015). voicethread.com 